\title{
Preparation, Properties and Encapsulation of High Thermostability Phase-change Material ${ }^{\star}$
}

\author{
Guo-Qing Zhang ${ }^{\mathrm{a}}$, Chang-Wei Cai ${ }^{\mathrm{a}}$, Guo-Cheng Zhu ${ }^{\mathrm{a}}$, Lan Zhou ${ }^{\mathrm{a}}$, \\ Guo-Jin Liu ${ }^{\mathrm{a}}$, Jiri Militky ${ }^{\mathrm{b}}$, Jaromir Marek ${ }^{\mathrm{c}}$, \\ Mohanapriya Venkataraman ${ }^{\mathrm{b}}$, Ju-Ming Yao ${ }^{\mathrm{a}, *}$ \\ ${ }^{a}$ Key Laboratory of Advanced Textile Materials and Manufacturing Technology, Ministry of Education, \\ Zhejiang Sci-Tech University, Hangzhou 310018, China \\ ${ }^{\mathrm{b}}$ Department of material engineering, Technical University of Liberec, Studentská 1402/2, Liberec, \\ 46117, Czech Republic \\ ${ }^{\mathrm{c}}$ Institute for Nanomaterials, Advanced Technologies and Innovations, Technical University of Liberec, \\ Studentská 1402/2, Liberec, 46117, Czech Republic
}

\begin{abstract}
Microcapsules containing phase change materials (PCM) have been attracting much attention due to its applications in many energy storage fields. However, most PCM microcapsules have relatively low thermostability with an onset decomposition temperature of about $150{ }^{\circ} \mathrm{C}$, which to some extent restricts their applications. In this study, high chain ester of dodecanol laurate was first synthesized with raw materials of 1-dodecanol and lauric acid by esterification reaction under catalysis, and then the ester as core material was encapsulated using PMMA by emulsion polymerization. The resultant products, including the ester and the PCM microcapsules, were respectively characterized by using infrared spectroscopy (IR), differential scanning calorimeter (DSC), thermogravimetry (TG), laser particle size analyzer and scanning electron microscope (SEM). The synthesized dodecanol laurate have a high purity according to IR spectrum analysis and suitable phase temperature range of $22-30{ }^{\circ} \mathrm{C}$ from DSC measurement. In addition, the ester also showed good thermal properties with a latent heat of 206 $\mathrm{J} / \mathrm{g}$, small super-cooling degree of $0.5{ }^{\circ} \mathrm{C}$ and high thermal evaporation temperature of $220{ }^{\circ} \mathrm{C}$, which would be very suitable for application in PCM energy storage materials. Using the above ester as core material, the PCM microcapsules were successfully fabricated by emulsification and polymerization processes. The prepared microcapsules showed perfect spherical shape with size about $865 \mathrm{~nm}$ and high heat storage performance with a latent energy of $118 \mathrm{~J} / \mathrm{g}$. Owing to high evaporation temperature of ester core material itself and further encapsulation, the prepared PCM microcapsules showed higher thermostability. TG results suggested that the microcapsules had a high onset weightless temperature which was over $252{ }^{\circ} \mathrm{C}$, it was a significant increment comparing to those PCM microcapsules reported by most literatures. Moreover, thermo-regulating cotton fibers were fabricated by using the above PCM microcapsules. It's seen that the PCM microcapsules deposited on the fibers uniformly and the fibers had a latent heat of $20.18 \mathrm{~J} / \mathrm{g}$.
\end{abstract}

Keywords: Esterification; PCM Microcapsules; Thermostability; Latent Heat

${ }^{\star}$ Project supported by The Key Program for International S\&T Innovation Cooperation Projects of China (Project No. 2016YFE0131400).

${ }^{*}$ Corresponding author.

Email address: yaoj@zstu.edu.cn (Ju-Ming Yao). 


\section{Introduction}

In recent decades, the use of phase change materials (PCMs) for thermal energy storage has attracted extensive attention owing to increasing energy consumption and environment problems [1]. Because they can store and release great amounts of energy when undergoing phase change process, PCMs showed great potential in applications for solar energy storage, thermo-sensors, food and medicine package and intelligent textiles or fabrics, etc [2-5]. Especially in smart textiles, since early 1980s PCMs were first used in astronaut suits to against the extreme temperature fluctuations in outer space $[6,7]$, thermo-regulating textiles have been successfully developed for they are able to create a much more effective barrier than conventional textiles to protect the human body from harsh conditions.

During the processing and usage of the thermo-regulating textiles, it is very important to prevent leakage of the PCMs in the phase change process. After much researches and practices, microencapsulation of PCMs is regarded as a considerably feasible solution [8, 9]. A lot of studies have been performed on microencapsulation of PCMs using some polymers or inorganic materials as shell [10-14]. The resultant microcapsules or its emulsion can be used to fabricate the temperature-regulating textiles by finishing or solution spinning.

With increasingly application fields, thermal properties of the PCM microcapsules, especially thermostability, has become an important criterion. In fact, many synthesized PCM microcapsules show lower onset decomposition temperature, which limited the use of the energy storage systems. A lot of researches reported the preparation and properties of the PCM microcapsules with paraffin or fatty acids as core and polymeror $\mathrm{SiO}_{2}$ as shell. However the thermogravimetric testing results suggest that the volatilization of n-octadecane from the capsules starts before $150{ }^{\circ} \mathrm{C}$ [15-24]. As well known, most fabrics will undergo heat treatment under temperature of over $150^{\circ} \mathrm{C}$ during finishing, which leads to remarkable loss of PCM from microcapsule.

The low thermostability of PCM microcapsules significantly cannot meet the high temperature heat treatment of textiles, the main reason for the poor thermostability of the PCM microcapsules is due to the lower thermal volatilization temperature of PCMs. So it is necessary to further develop new high thermostability PCMs. Up to now, lots of PCMs have been discovered, but very few of them can be used for textile applications since the PCMs in textiles are required to have suitable temperature range, high latent heat capacity, stable chemical property, to be nontoxic and comfort. According to the above requirements, a few kinds of PCMs, such as paraffin, fatty acid and alcohol or their eutectics, are widely used in the fabrication of thermo-regulating textiles. Among these organic PCMs, fatty acids are preferred due to theirs high latent heat, broad phase change temperature range and low cost. But most of fatty acids including their eutectics also show low heat volatility temperature of about $140{ }^{\circ} \mathrm{C}$.

Recent years, fatty acid esters, as new PCMs, gradually draw many researchers' attention because of their high latent heat and thermostability. Most fatty acid esters have an onset decomposition of above $200{ }^{\circ} \mathrm{C}$ due to their higher chain length comparing to relevant fatty acid, which is significantly more suitable for those high temperature application conditions.

The objective of this work is dedicated to fabricate the high thermostability fatty acid ester and further encapsulation with it as core material. It is expected the prepared PCM microcapsules have good thermostability, high latent heat and small size to meet the application in the solution spinning. For the fabrication of thermo-regulating fibers, solution spinning is currently the most feasible method. In general, the thermo-regulating fibers can be prepared by adding 
PCM microcapsules into spinning solution. Therefore, it is a research focus to fabricate PCM capsules with small grain size and good stability.

\section{Experimental}

\subsection{Materials}

The reagents, including 1-dodecanol, lauricacid, ferric chloride hexahydrate $\left(\mathrm{FeCl}_{3} \cdot 6 \mathrm{H}_{2} \mathrm{O}\right)$, Methyl methacrylate (MMA) and 2,2'-Azobisisobutyronitrile (AIBN), was purchased from Aladdin Industrial Corporation (Shanghai China). N-Hexadecyltrimethylammonium Chloride (CTAC), mesitylene andacetone were purchased from Hangzhou Huipu Chemical Industry Co., Ltd. (Hangzhou, China). All above chemicals were used without further purification during the experiments.

\subsection{Synthesis of High-chain Fatty Acid Ester}

The high-chain fatty acid esters of dodecanol and lauric acid were synthesized and purified according to the method published in literatures [25-27]. The esterification was carried out in a single-necked flask equipped with magnetic stirring and a Dean-Stark apparatus surmounted with a reflux condenser. Equimolar amounts of dodecanol, lauricacid and $2 \mathrm{~mol} \%$ ferric chloride were mixed in the round-bottomed flask with a certain amount of mesitylene. The mixture was heated to reflux in boiling mesitylene $\left(162{ }^{\circ} \mathrm{C}\right)$ for $24 \mathrm{~h}$, and then the ester product was obtained by filtration and further purified by crystallization in acetone.

\subsection{Preparation of PCM Microcapsules}

The synthesized ester was encapsulated with PMMA as shell by emulsion polymerization. In a typical experiment, $24 \mathrm{~g}$ PCMs, $12 \mathrm{~g}$ MMA monomer, $0.2 \mathrm{~g}$ AIBN and $1.76 \mathrm{~g}$ CTAC were successively added into $144 \mathrm{ml}$ deionized water and sheared for 10 minutes $(20000 \mathrm{rpm})$ at a temperature of $45^{\circ} \mathrm{C}$ by using a homogenizer (IKA model T25). The above suspension was then put into a three-necked flask and heated up to $75^{\circ} \mathrm{C}$ under a constant rotation of $300 \mathrm{rpm}$ in a $\mathrm{N}_{2}$ purge atmosphere. The preparation route was schemed as Fig. 1.

After 12 hours polymerization, homogenous PCM microcapsule emulsion was obtained and then cooled down to zero degree for one hour to erase the unwrapped core material. The PCM microcapsule powders were collected by filtering above emulsion, and then washed with distilled water and n-hexane.

Cotton fabrics were dipped into microcapsule emulsions for 5 minutes and then dried in a laboratory oven for 10 minutes at a temperature of $100{ }^{\circ} \mathrm{C}$, the resultant fabrics were then tested using SEM and DSC.

\subsection{Characterization of the Ester and PCM Microcapsules}

FT-IR spectra of the starting raw materials, synthesized ester and PCM microcapsules were collected on a Nicolet 5700 spectrometer (ThermoFisher, USA) with universal ATR accessory 


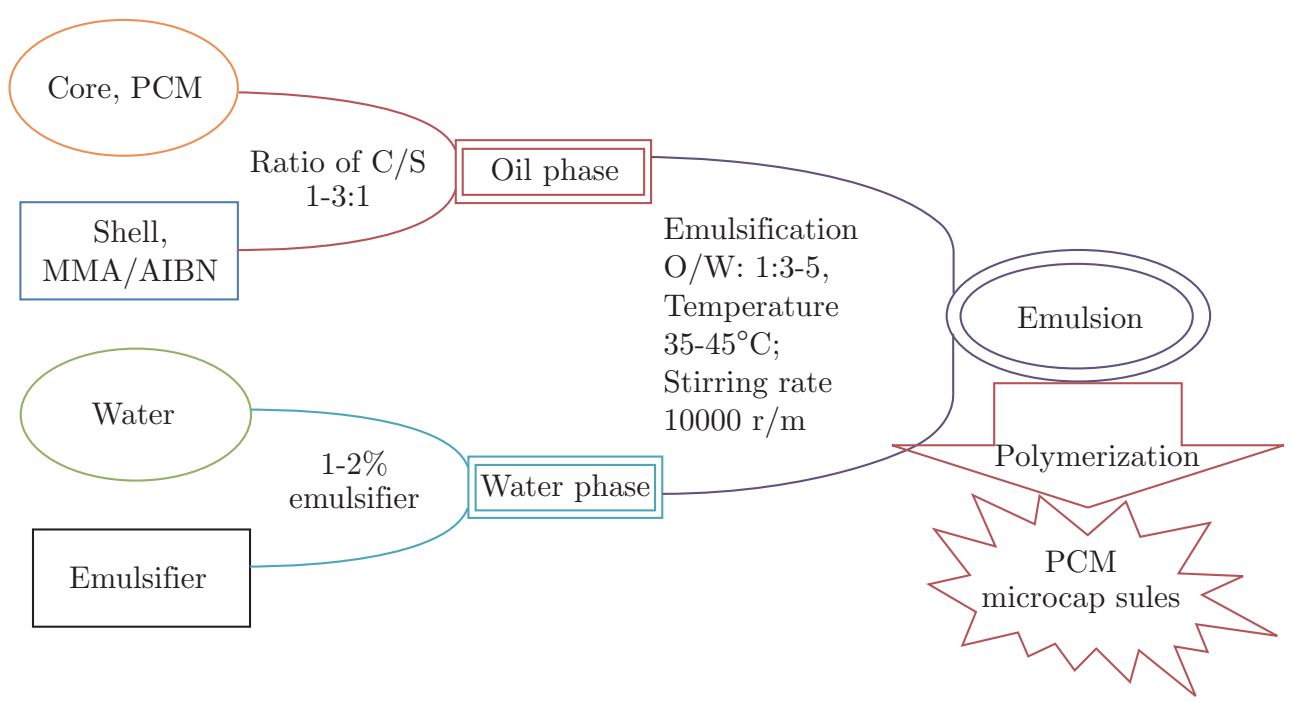

Fig. 1: The preparation route of PCM microcapsules

between $4000-400 \mathrm{~cm}^{-1}$ wavelengths.

The size distribution of the microcapsules was analyzed on a Malvern Instruments Master Sizer (Worcestershire, U.K.).

The morphology of the microcapsules and the thermo-regulating cotton fibers were observed after coated with Au on a JEOL 5610 scanning electron microscope. All samples were sputter coated with gold under vacuum and then observed with acceleration voltage of $5 \mathrm{kV}$.

Thermal behaviors of the PCM ester, the PCM microcapsules and the thermo-regulating cotton fibers were tested using a differential scanning calorimetry (PYRIS Diamond DSC, PerkinElmer, USA).The specimens were first weighted accurately and sealed in aluminum pans. The testing was then performed within a temperature range from 0 to $50{ }^{\circ} \mathrm{C}$ at a heating and cooling rate of $10{ }^{\circ} \mathrm{C} /$ min under a $20 \mathrm{ml} / \mathrm{min} \mathrm{N}_{2}$ gas purge.

Thermal degradation processes of the PCM ester and the PCM microcapsules were recorded on a thermogravimetry analyzer (PYRIS1 TGA, PerkinElmer, USA) with temperature from $40{ }^{\circ} \mathrm{C}$ to $500{ }^{\circ} \mathrm{C}$ at a heating rate of $10{ }^{\circ} \mathrm{C} / \mathrm{min}$ under a $20 \mathrm{ml} / \mathrm{min} \mathrm{N}_{2}$ gas purge. The decomposition behavior, including onset and $5 \%$ weightless temperatures were calculated and analyzed.

\section{Results and Discussion}

\subsection{Synthesis and Characterization of Lauric dodecanoate}

The esterification reaction was successfully carried out using $\mathrm{FeCl}_{3}$ as catalyst and mesitylene as solvent [27]. $\mathrm{FeCl}_{3}$ shows excellent catalytic activity during the reaction because of hydrolyzed cationic species of the $\mathrm{Fe}^{3+}$. In addition, mesitylene can bring the by-product water out by reflux of mesitylene, which further increase the esterification reaction degree. The purity of the synthesized lauric dodecanoate was analyzed by FT-IR spectroscopy and its thermal properties were also tested by DSC and TG.

FT-IR spectroscopy has been commonly used to verify whether the ester was successfully syn- 
thesized or not. In this study, the reactants, including 1-dodecanol and lauric acid, contain alkane, carbonyl and hydroxyl groups, which give significant absorptions on the IR curves.

In general, fatty acids show very broad trough of bonded oxygen-hydrogen stretching vibrations between 2500 and $2700 \mathrm{~cm}^{-1}$ and fatty alcohols have a similar trough at higher wave numbers in the range of $3230-3550 \mathrm{~cm}^{-1}$. The characteristic carbonyl stretching vibration of saturated fatty acids usually absorbs in the range of $1700-1725 \mathrm{~cm}^{-1}$ but the absorption peak will shift to 1730-1 $740 \mathrm{~cm}^{-1}$ after esterification. This change of carbonyl stretching vibration is always used to estimate the esterification reaction degree. The intensity of the absorption peak at $1710 \mathrm{~cm}^{-1}$ will gradually decrease but the peak at $1735 \mathrm{~cm}^{-1}$ peak swell significantly during the esterification reaction.

As a comparison, the IR spectra of the mixed raw materials and the ester product were collected and shown in Fig. 2. It is clear that there is much difference on the two IR spectra before and after esterification reaction, one can estimate the reaction degree and the product purity by analysis of IR spectrum.
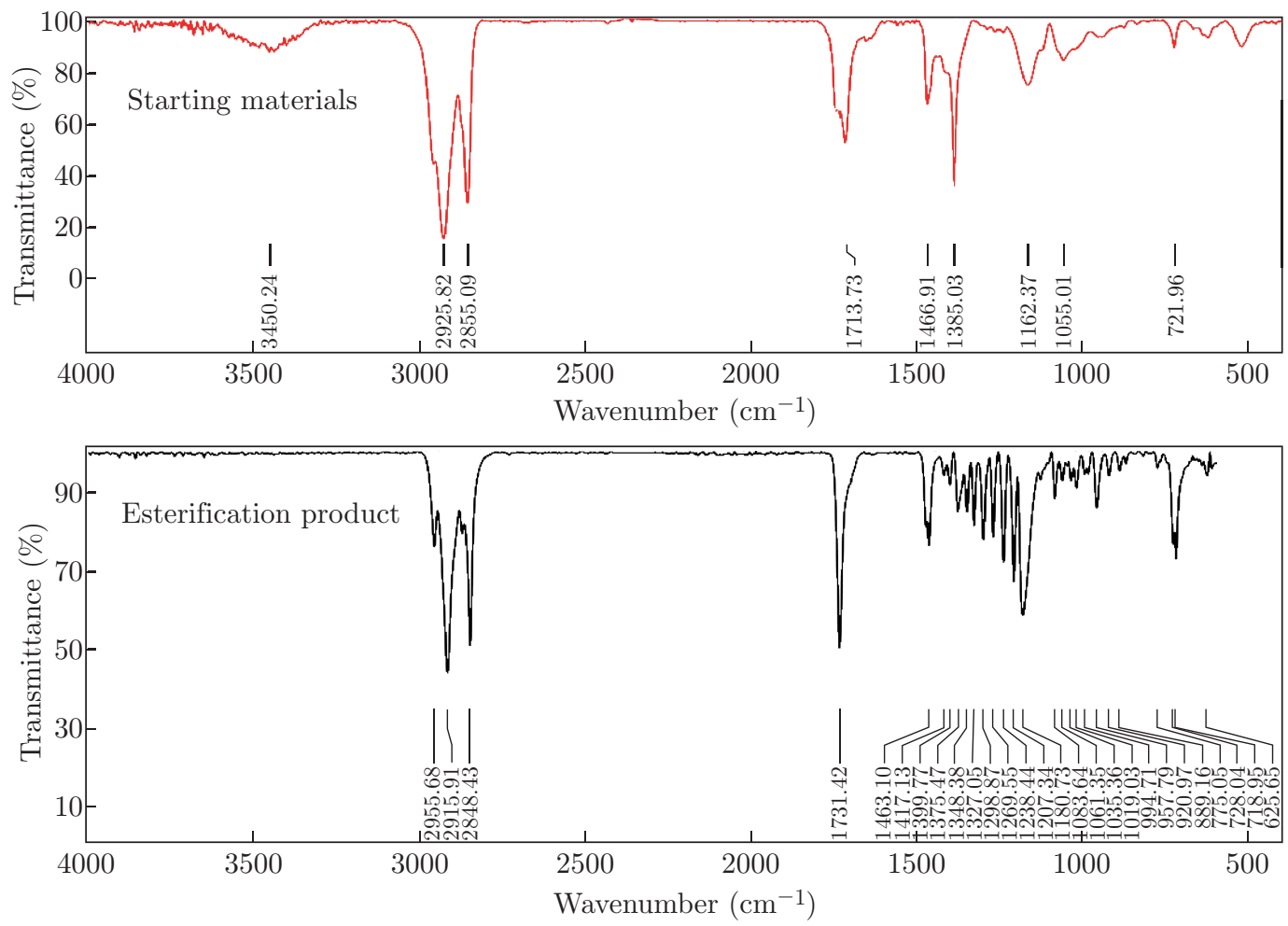

Fig. 2: The IR spectra of the starting materisls and the sythesized lauric dodecanoate

From Fig. 2, the IR spectrum of the starting materials shows the characteristic peaks at 3450 and $1731 \mathrm{~cm}^{-1}$ corresponding to the hydroxyl and carbonyl, respectively, which attributes to the reactants 1-dodecanol and lauric acid. After esterification reaction, one can see that the above hydroxyl and carbonyl absorption peaks disappear from the IR spectrum of esterification product, while the carbonyl stretching vibration of acyclic saturated ester is at around $1731 \mathrm{~cm}^{-1}$.

Above results confirm that the esterification reaction completed successfully and a pure ester product was obtained. High purity lauric dodecanoate significantly has better thermal properties and is suitable to be phase change material.

Thermal properties, such as phase change temperature, latent heat, super cooling degree and 
onset decomposition temperature, are the key evaluation indexes for the PCM. The thermal behaviors of the ester were measured by DSC and TG and the results are shown in Fig. 3.
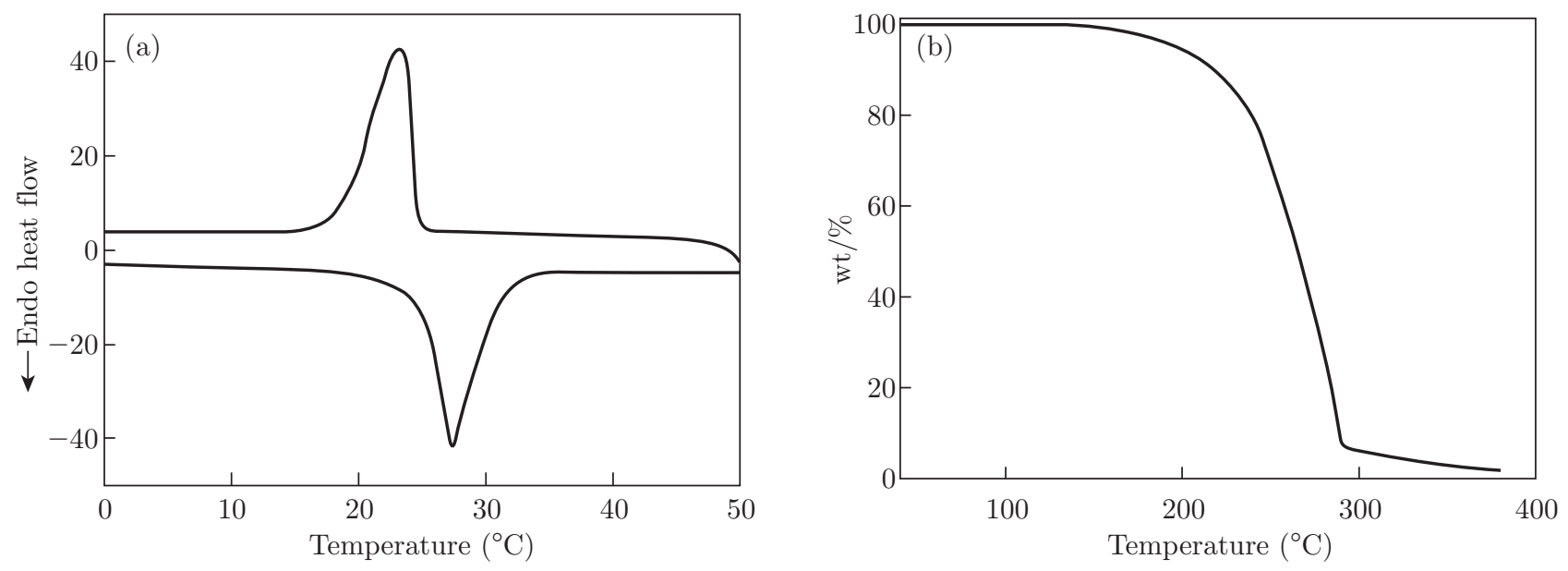

Fig. 3: DSC (a) and TG (b) scans of the synthesized ester

From Fig. 3(a), the DSC curve of the obtained lauric dodecanoate shows typical phase change process in the temperature range of $22-30{ }^{\circ} \mathrm{C}$ where a large amount of heat was absorbed and released with solid-liquid transition. The melting and freezing temperatures and latent heat of the ester were measured to be $28.12{ }^{\circ} \mathrm{C}$ and $22.25^{\circ} \mathrm{C}$ and $206.20 \mathrm{~J} / \mathrm{g}$, respectively. It is well known that this temperature range is very comfortable temperature range for human body. Meanwhile, the ester has a very promising phase change enthalpy of above $200 \mathrm{~J} / \mathrm{g}$, which is higher than most of the inorganic and organic PCMs.

In addition, it has been stated that a good PCM should have small super-cooling degree [28]. According to the measured onset temperatures of melting and freezing, it can be concluded that the synthesized lauric dodecanoate has a very narrow super-cooling degree of $0.5{ }^{\circ} \mathrm{C}$. The small temperature difference between melting and freezing indicates that the phase change process occurs congruently and homogeneously.

Besides thermostability is also an important criterion for PCMs, which determine their application range and liability. TGA can be used to evaluate the thermostability of the PCMs by measuring onset weightless temperature that the material can withstand without chemical decomposition. In fact, most of organic PCMs like high chain $n$-alkane, fatty alcohols and acids and their eutectoids are prone to heat volatilization rather than decomposition under high temperature.

Therefore the heat volatilization temperatures should be taken into consideration in selecting the encapsulation type and application area for utilization of PCMs. For instance, the PCMs used in textiles and building materials are expected to have high volatilization point because they will undergo high temperature treatment during the processing, such as heat-setting of the textile.

TGA curve of the synthesized lauric dodecanoate is shown in Fig. 3(b), where onset heat volatilization temperature is determined to be $220{ }^{\circ} \mathrm{C}$. Organic PCMs with phase change temperature range of $20-35{ }^{\circ} \mathrm{C}$, such as $n$-octadecane, dodecanol and mixture of long chain fatty alcohol and acid, basically start to evaporate before $140{ }^{\circ} \mathrm{C}$. This is mainly due to their low carbon chain number, therefore it is a feasible way to improve the thermostability of the PCMs by increasing carbon chain number, for example esterification of fatty alcohol and acid.

In fact for a fatty acid, the increase of carbon chain length after esterification actually improved 
the thermostabiity and durability of the PCM material, which resulted in a much higher onset volatilization temperature. As another evaluation index, the $5 \%$ weight loss temperature of the present high-chain ester is above $250{ }^{\circ} \mathrm{C}$. Thus, the ester PCM materials can easily withstand a heat processing at around $200{ }^{\circ} \mathrm{C}$ without any thermal decomposition. This increment undoubtedly improves the PCM performance against high temperature, which would further expand its application field.

\subsection{Encapsulation of the Synthesized Ester}

The synthesized lauric dodecanoate was encapsulated by emulsion polymerization. Compared with fatty alcohol and acid or their eutectoids, carbon chain length of the synthesized ester is roughly doubled, which will be helpful to the encapsulation effect due to the disappearance of polar groups such as the hydroxyl and carbonyl. During the emulsion and polymerization, no any demulsification and implosion occurred, which indicates that the polymerization is facial and complete.

Particle size and shape can noticeably change physical and real properties of an encapsulated PCM. In this sense, the geometric shape of the synthesized PMMA/ester microcapsules was examined using SEM technique. The SEM images of the prepared microcapsules are shown in Fig. 4.

Fig. 4(a) and (b) show the SEM micrographs of PMMA/ester capsules under different magnifications. It looks that few broken capsules can be found in the product, which suggest there is a high polymerization degree during the reaction. As shown in these images, the capsules have spherical profile with fairly uniform structure and compact surfaces. It is clear that the microcapsule particles are homogenous and its average size is estimated to be around $1 \mu \mathrm{m}$.
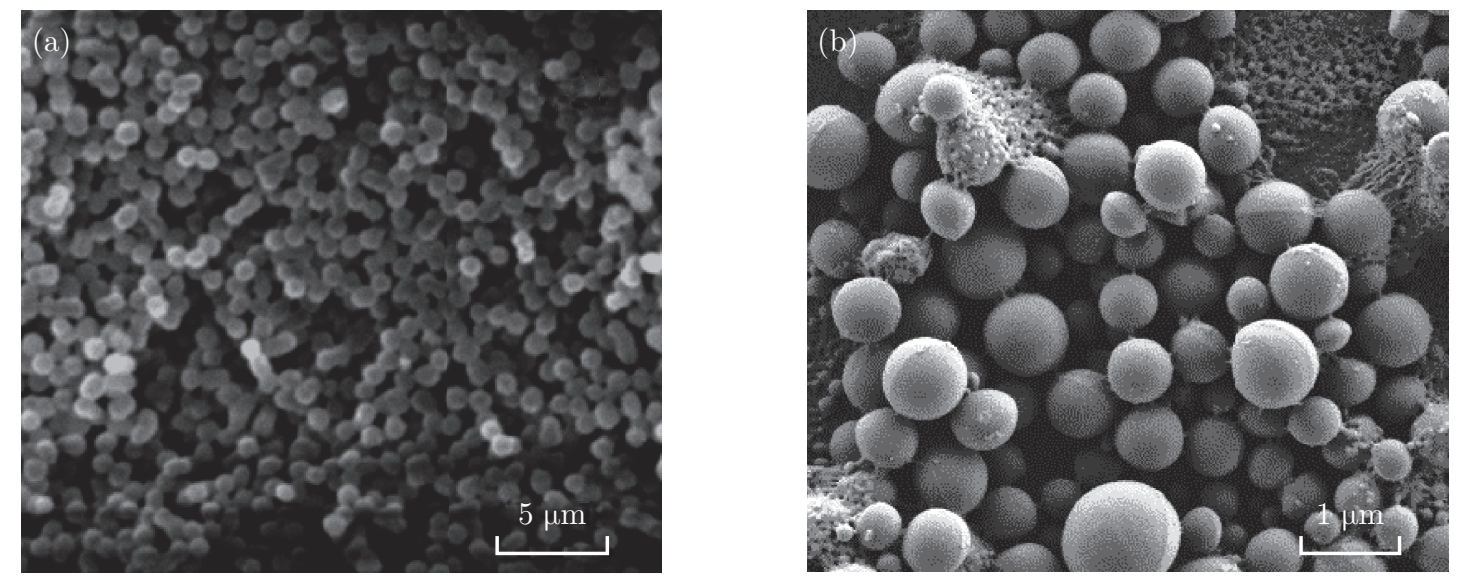

Fig. 4: The SEM images of the prepared PCM microcapsules under different magnifications

The SEM results just stand for local information, in order to further verify the size and distribution of the prepared PCM microcapsules, the synthesized microcapsules emulsion was measured using a laser particle size analyzer and the result was shown in Fig. 5.

From Fig. 5, it can be seen that there is only one peak on the size distribution curve which means the PCM capsules have good monodispersity. The microcapsule size is very concentrated in the range of $430 \mathrm{~nm}$ to $1800 \mathrm{~nm}$ and its mean size was calculated to be D90 865(6) nm. The small particle size and centralized distribution is very suitable for some special applications, such 


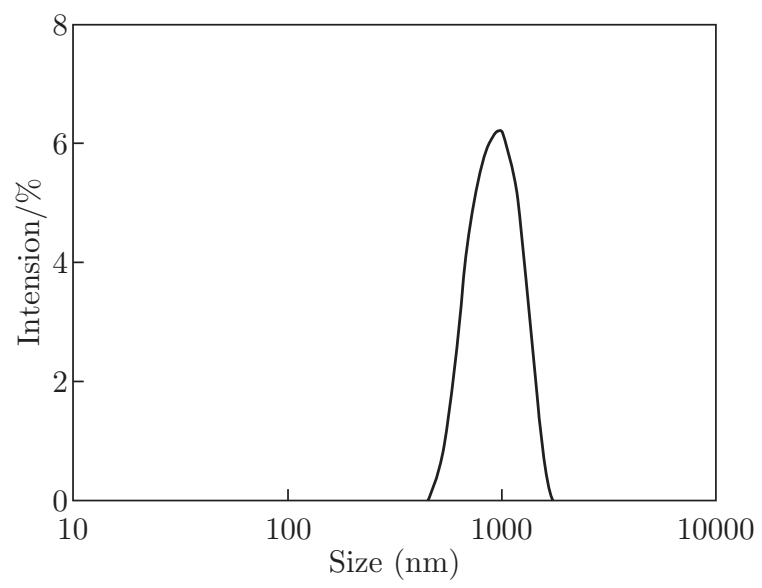

Fig. 5: Size distribution of the synthesized PCM microcapsules emulsion

as thermo-regulated fibers by solution spinning, where need the size of the filler particles to less 1 $\mu \mathrm{m}$ due to the diameter of the spinning fibers is small to be about $20 \mu \mathrm{m}$. Thus small size PCM microcapsules can meet many special application fields.

As key index of the PCM product, the thermal properties of the sythesized microcapsulesdirectly affect its application. In this study, based on the synthesized ester with high heat enthalpy and thermostability, the prepared PMMA/ester microcapsules show excellent thermal propties.

As compasion, the DSC and TG measurement resutls of the PCM microcapsules together with the ester are shown in Fig. 6 and relavant calculated parameters listed in Table 1.
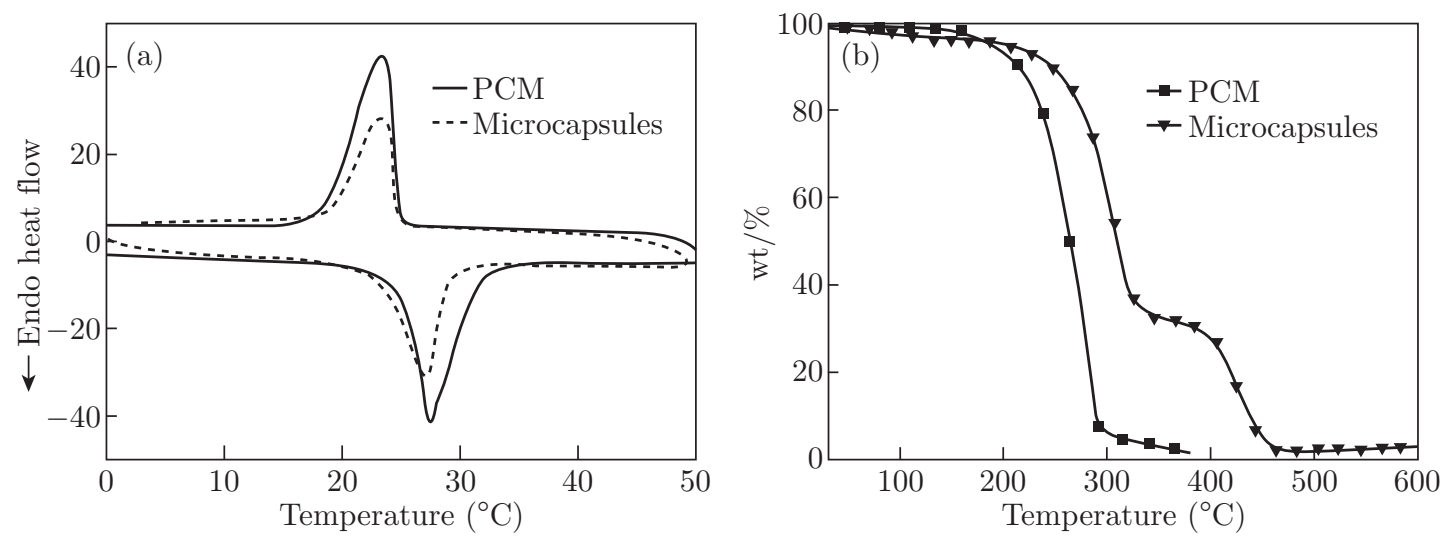

Fig. 6: The DSC and TG measurement curves of the prepared PMMA/ester microcapsules together with the synthesized ester

As the overlapped DSC curves shown in Fig. 6(a), just like the PCM ester, the microcapsules exhibit the same phase change behaviors during heating and cooling processes. From Table 1, the temperatures of melting and freezing and supercooling degree were respectively determined as $27.85{ }^{\circ} \mathrm{C}, 22.91{ }^{\circ} \mathrm{C}$ and $0.48{ }^{\circ} \mathrm{C}$ for the PMMA/ester microcapsules, which is basically consistent with that of the ester. The latent heats of melting and freezing were calculated to be 118.25 and $115.69 \mathrm{~J} / \mathrm{g}$ for PMMA/ester microcapsules, respectively. It is significantly reasonable according to the feed ratio $(2: 1)$ of the core and shell materials, which suggest that the encapsulation degree of the prepared PCM microcapsules is up to $87 \%$.

The thermal stabilities of the esters and PMMA/ester microcapsules were also evaluated by 
Table 1: The DSC data of both the synthesized PCM microcapsules and ester

\begin{tabular}{cccccccc}
\hline Sample & $T_{\mathrm{om}}\left({ }^{\circ} \mathrm{C}\right)$ & $T_{\mathrm{pm}}\left({ }^{\circ} \mathrm{C}\right)$ & $\Delta H_{\mathrm{m}}(\mathrm{J} / \mathrm{g})$ & $T_{\mathrm{oc}}\left({ }^{\circ} \mathrm{C}\right)$ & $T_{\mathrm{pc}}\left({ }^{\circ} \mathrm{C}\right)$ & $\Delta H_{\mathrm{c}}(\mathrm{J} / \mathrm{g})$ & $\Delta T\left({ }^{\circ} \mathrm{C}\right)$ \\
\hline Lauric dodecanoate & $24.25(8)$ & $28.12(5)$ & $206.20(7)$ & $23.75(8)$ & $22.25(3)$ & $204.73(6)$ & 0.50 \\
PCM microcapsules & $23.62(3)$ & $27.85(4)$ & $118.25(9)$ & $23.10(4)$ & $22.91(5)$ & $115.69(4)$ & 0.52 \\
\hline
\end{tabular}

Note: $T_{\mathrm{om}}$ represents onset melting temperature; $T_{\mathrm{pm}}$ represents melting peak temperature; $T_{\mathrm{oc}}$ represents onset cooling temperature; $T_{\mathrm{pc}}$ represents cooling peak temperature; $\Delta H_{\mathrm{m}}$ represents melting enthalpy; $\Delta H_{\mathrm{c}}$ represents solidification enthalpy; $\Delta T$ represents supercooling degree.

means of TGA as shown in Fig. 6(b). It can be seen that there is a single degradation process from $200{ }^{\circ} \mathrm{C}$ to $310^{\circ} \mathrm{C}$ for the lauric dodecanoate, but it is two steps for the PCM microcapsules. Where the first one occurring in the temperature range of $230-350{ }^{\circ} \mathrm{C}$ is related with the evaporation of the esters sealed in the microcapsules, while the second step in $400-490{ }^{\circ} \mathrm{C}$ is attributed to the degradation of the PMMA shell.

The onset decomposition temperature, $5 \%$ weight loss temperature, temperature of maximum decomposition and weight loss percent are presented in Table 2. From the results, one can see that $T_{\text {od }}, T_{5 \mathrm{wt} \%}, T_{\max }$ and $T_{\text {ed }}$ of the microcapsules are largely higher than those of pure core material. An increment of about $30{ }^{\circ} \mathrm{C}$ indicates that encapsulation can further improve the stability of the PCM.

Table 2: The TGA data of both the PCM microcapsules and ester

\begin{tabular}{ccccccc}
\hline Sample & $T_{\text {od }}\left({ }^{\circ} \mathrm{C}\right)$ & $T_{5 \mathrm{wt} \%}\left({ }^{\circ} \mathrm{C}\right)$ & $T_{\max }\left({ }^{\circ} \mathrm{C}\right)$ & $T_{\text {ed }}\left({ }^{\circ} \mathrm{C}\right)$ & $\Delta Y(\mathrm{wt} \%)$ \\
\hline Lauric dodecanoate & & $220.32(2)$ & $238.12(5)$ & $268.56(7)$ & $302.25(6)$ & $95.73(4)$ \\
\multirow{2}{*}{ PCM microcapsules } & 1st step & $250.12(4)$ & $267.85(2)$ & $313.10(8)$ & $382.86(3)$ & $62.08(5)$ \\
& 2nd step & $402.23(3)$ & $408.10(1)$ & $431.56(4)$ & $463.42(5)$ & $36.22(7)$ \\
\hline
\end{tabular}

Note: $T_{\text {od }}$ represents onset decomposition temperature; $T_{5 \mathrm{wt}} \%$ represents $5 \%$ weight loss temperature; $T_{\max }$ represents maximum decomposition temperature; $T_{\text {ed }}$ represents ending decomposition temperature; $\Delta Y$ represents weight loss percent.

In addition, both onset decomposition temperature and $5 \%$ weight loss temperature of the PCM microcapsules are higher than $250{ }^{\circ} \mathrm{C}$. This means that the fabricated PCM microcapsules can withstand high temperature heat treatment processing. Moreover, the weight loss percent regarding the first stage is determined as about $62 \%$, which is well agree with the encapsulation ratio calculated by considering the DSC data.

Above results suggest that PCM microcapsules with high latent heat, small size and high thermostability can be successfully fabricated by emulsion polymerization by using the synthesized ester as core material. Owning to its prominent thermostability, the PCM microcapsules are potential energy storage material and expected to be applied for the preparation of thermoregulating fibers by solution spinning.

\subsection{Application of the PCM Microcapsules}

The increment in mass of the cotton fiber before and after dipping treatment reached to $15.66 \%$, which suggested that large amount of PCM microcapsules were deposited on the fibers. Then 
SEM and DSC testing of the thermo-regulating cotton fibers were carried out after washing.

The SEM images of the prepared thermo-regulating cotton fibers are given in Fig. 7. It can be observed that lots of PCM microcapsules were adhered on the surface of the cotton fibers and the gaps between the fibers.
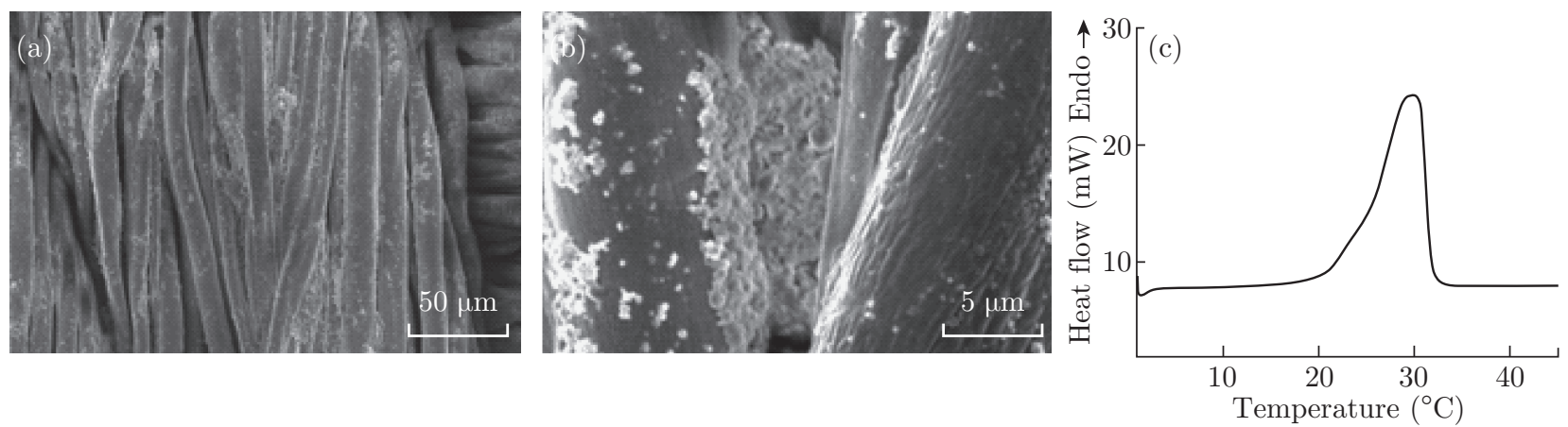

Fig. 7: SEM images of the thermo-regulating cottonfibers (a) 500×; (b) 5000×; and (c) DSC scan of the fibers

The latent heat of the thermo-regulating fibers was measured by DSC, the melting occurred in a range of $21.68 \sim 32.23{ }^{\circ} \mathrm{C}$ with a melting enthalpy of $20.18 \mathrm{~J} / \mathrm{g}$. Based on the above results, the prepared PCM microcapsules are suitable for thermal comfortable textiles.

\section{Conclusion}

In the study, a novel ester PCM material, lauric dodecanoate, was successfully synthesized by esterification using 1-dodecanol and lauric acid. The synthesized dodecanol laurate showed high purity, suitable phase change temperature range, good thermal properties with latent heat of 206 $\mathrm{J} / \mathrm{g}$, small supercooling degree of $0.5^{\circ} \mathrm{C}$ and high thermal evaporation temperature of $220{ }^{\circ} \mathrm{C}$, which is very suitable for application in PCM energy storage materials.

By using lauric dodecanoate as core material, the PCM microcapsules were successfully fabricated by emulsion polymerization. The prepared microcapsules showed perfect spherical shape with mean size about $865 \mathrm{~nm}$ and high heat storage performance with a latent energy of 118 $\mathrm{J} / \mathrm{g}$. The prepared PCM microcapsules also showed higher thermostability with an onset decomposition temperature of $250{ }^{\circ} \mathrm{C}$, which is a significant improvement comparing with those PCM microcapsules reported in literatures. The application for the thermo-regulating cotton fibers indicates that the PCM capsules can be treated on the fibers in abundance with a high latent heat. The excellent performance of the developed PCM microcapsules would undoubtedly be a very promising energy storage material.

\section{Acknowledgment}

The work was supported by the project of The Key Program for International S\&T Innovation Cooperation Projects of China (Project No. 2016YFE0131400). 


\section{References}

[1] Francis A, Hewitt N, Eames P, Smyth M. A review of materials, heat transfer and phase change problem formulation for latent heat thermal energy storage systems (LHTESS). Renewable and Sustainable Energy Reviews: 2010; 14(2); 615-628.

[2] Karthikeyan M, Ramachandran T. Review of thermal energy storage of micro- and nanoencapsulated phase change materials. Materials Research Innovations: 2014; 18(7); 541-554.

[3] Gao F, Wang X, Wu D. Design and fabrication of bifunctional microcapsules for solar thermal energy storage and solar photocatalysis by encapsulating paraffin phase change material into cuprous oxide. Solar Energy Materials and Solar Cells: 2017; 168; 146-164.

[4] Sami S, Sadrameli SM, Etesami N. Thermal properties optimization of microencapsulated a renewable and non-toxic phase change material with a polystyrene shell for thermal energy storage systems. Applied Thermal Engineering: 2018; 130; 1416-1424.

[5] Alay S, Göde F, Alkan C. Preparation and characterization of poly(methylmethacrylate-coglycidyl methacrylate)/n-hexadecane nanocapsules as a fiber additive for thermal energy storage. Fibers and Polymers: 2010; 11(8); 1089-1093.

[6] Mulligan J C, Colvin D P, Bryant Y G. Microencapsulated phase-change material suspensions for heat transfer in spacecraft thermal systems. Journal of spacecraft and rockets: 1996; 33(2); $278-284$.

[7] Zhang X. Heat-storage and thermo-regulated textiles and clothing. Smart fibers and clothing. Woodhead Publishing, Cambridge, 2001; 34-57.

[8] Song S, Dong L, Qu Z, Ren J, Xiong C. Microencapsulated capric-stearic acid with silica shell as a novel phase change material for thermal energy storage. Applied Thermal Engineering: 2014; $70(1) ; 546-551$.

[9] Ma Y, Zong J, Li W, Chen L, Tang X, Han N, Wang J, Zhang X. Synthesis and characterization of thermal energy storage microencapsulated n-dodecanol with acrylic polymer shell. Energy: 2015; 87; 86-94.

[10] Qiu X, Lu L, Zhang Z, Tang G, Song G. Preparation, thermal property, and thermal stability of microencapsulated n-octadecane with poly(stearyl methacrylate) as shell. Journal of Thermal Analysis and Calorimetry: 2014; 118(3); 1441-1449.

[11] Zhang T, Wang Y, Shi H, Yang W. Fabrication and performances of new kind microencapsulated phase change material based on stearic acid core and polycarbonate shell. Energy Conversion and Management: 2012; 64; 1-7.

[12] Chang CC, Tsai YL, Chiu JJ, Chen H. Preparation of Phase Change Materials Microcapsules by Using PMMA Network-Silica Hybrid Shell Via Sol-Gel Process. Journal of Applied Polymer Science: 2009; 112(3); 1850-1857.

[13] Alkan C, Sarı A, Karaipekli A. Preparation, thermal properties and thermal reliability of microencapsulated n-eicosane as novel phase change material for thermal energy storage. Energy Conversion and Management: 2011; 52(1); 687-692.

[14] Pan L, Tao Q, Zhang S, Wang S, Zhang J, Wang S, Zhang Z. Preparation, characterization and thermal properties of micro-encapsulated phase change materials. Solar Energy Materials and Solar Cells: 2012; 98; 66-70.

[15] Liang S, Li Q, Zhu Y, Chen K, Tian C, Wang J, Bai R. Nanoencapsulation of n-octadecane phase change material with silica shell through interfacial hydrolysis and polycondensation in miniemulsion. Energy: 2015; 93; 1684-1692.

[16] Konuklu Y, Paksoy H O, Unal M. Nanoencapsulation of n-alkanes with poly(styrene-co-ethylacrylate) shells for thermal energy storage. Applied Energy: 2015; 150;335-340. 
[17] Sarı A, Alkan C, Bilgin C. Micro/nano encapsulation of some paraffin eutectic mixtures with poly(methyl methacrylate) shell: Preparation, characterization and latent heat thermal energy storage properties. Applied Energy: 2014; 136 (Supplement C); 217-227.

[18] Sarı A, Alkan C, Döğüşcü DK, Kızıl C. Micro/nano encapsulated n-tetracosane and n-octadecane eutectic mixture with polystyrene shell for low-temperature latent heat thermal energy storage applications. Solar Energy: 2015; 115:195-203.

[19] Fang Y, Wei H, Liang X, Wang S, Liu X, Gao X, Zhang Z. Preparation and Thermal Performance of Silica/n-Tetradecane Microencapsulated Phase Change Material for Cold Energy Storage. Energy \& Fuels: 2016; 30(11); 9652-9657.

[20] Sarı A, Alkan C, Kahraman Döğüşcü D, Biçer A. Micro/nano-encapsulated n-heptadecane with polystyrene shell for latent heat thermal energy storage. Solar Energy Materials and Solar Cells: 2014; 126(Supplement C); 42-50.

[21] Qiu X, Lu L, Wang J, Tang G, Song G. Preparation and characterization of microencapsulated n-octadecane as phase change material with different n-butyl methacrylate-based copolymer shells. Solar Energy Materials and Solar Cells: 2014; 128(Supplement C); 102-111.

[22] Konuklu Y, Paksoy HO, Unal M, Konuklu S. Microencapsulation of a fatty acid with Poly(melamineurea-formaldehyde). Energy Conversion and Management: 2014; 80 (Supplement C); 382-390.

[23] Ma Y, Chu X, Tang G, Yao Y. The effect of different soft segments on the formation and properties of binary core microencapsulated phase change materials with polyurea/polyurethane double shell. Journal of Colloid and Interface Science: 2013; 392(Supplement C); 407-414.

[24] Döğüşü DK, Altıntaş A, Sarı A, Alkan C. Polystyrene microcapsules with palmitic-capric acid eutectic mixture as building thermal energy storage materials. Energy and Buildings: 2017; 150; 376-382.

[25] Ayd $\imath$ AA, Okutan H.High-chain fatty acid esters of myristyl alcohol with even carbon number: Novel organic phase change materials for thermal energy storage-1. Solar Energy Materials and Solar Cells: 2011; 95(10); 2752-2762.

[26] Ayd $\imath$ AA, Okutan H. High-chain fatty acid esters of myristyl alcohol with odd carbon number: Novel organic phase change materials for thermal energy storage-2. Solar Energy Materials and Solar Cells: 2011; 95(8); 2417-2423.

[27] Mantri K, Nakamura R, Komura K, Sugi Y. Esterification of Long Chain Aliphatic Acids with Long Chain Alcohols Catalyzed by Multi-valent Metal Salts. Chemistry Letters: 2005; 34(11); 1502-1503.

[28] Kenisarin M, Mahkamov K. Solar energy storage using phase change materials. Renewable and Sustainable Energy Reviews: 2007; 11(9); 1913-1965. 